\title{
Experimentation and problem-based learning as alternative for the science teaching
}

Soares, C.B. ${ }^{1}$; Coutinho, R. ${ }^{2}$; Escoto, D.F. ${ }^{1}$; Puntel, R.L. ${ }^{2,3}$; Folmer, V. ${ }^{2,3}$; Barbosa, N.B.V. ${ }^{2}$

${ }^{1}$ Licenciatura em Ciências da Natureza, Campus Uruguaiana, Universidade Federal do Pampa; ${ }^{2}$ PPG Educação em Ciências: Química da Vida e Saúde, Centro de Ciências Naturais e Exatas, Universidade Federal de Santa Maria;

${ }^{3}$ PPG Bioquímica, Campus Uruguaiana, Universidade Federal do Pampa

Experimentation and problem-based learning may aid to diminish the lack of student interest in science teaching and its contents. These tools help in understanding and in approaches in the scientific method to contextualize and give meaning to science teaching. Thus, this descriptive study presents an alternative developed from experimental activities carried out in short courses to 185 students from public schools in Uruguaiana-RS. With the problem-based learning, seven courses were offered in the period 2010-2011 lasting for five days. The courses were divided into four stages: problematization, with the theme "The food and our health"; experiment and theory, these phases occur together, where students define the protocol to be followed in order to try to answer questions experimentally using books and internet to sustain the practice theoretically; and closing, the students show the results of experiments carried out during the course through theater, music, posters or slides. Since students are the agents responsible for the development of this work the experimental activities through learning situations based on problems triggered a strong interest and involvement of students in the school contents. In conclusion, this method of experimentation and problem-based learning instigates the interest by scientific knowledge and turns the teaching of science in a practice innovative teaching.

Key-words: Science teaching; Problematization; Experimentation.

Supported by: FAPERGS, CNPq and CAPES. 